\title{
Effect of age, sex, and diurnal variation on the human fibrinolytic system
}

\author{
R. D. MANN \\ From the Clinical Research Department, Pfizer Limited, Sandwich, Kent
}

SYNOPSIS Fibrinolytic activity, as shown by the dilute blood clot lysis time, tends to show a diurnal variation, but is relatively unaffected by age and sex.

Mean plasma anti-urokinase activity is consistently and significantly greater in females in the post-menstrual week than in age-matched males, but is relatively unaffected by daily variation and age. This sex difference in the activity of plasma, which is inhibitory to fibrinolysis, is of a degree which makes this measurement important in studies of the fibrinolytic system in healthy persons and disease states.

This communication reports the results of a study to determine the effect of age, sex, and diurnal variation on the fibrinolytic activity of blood, and the activity of plasma which is inhibitory to urokinase-activated fibrinolysis.

Dissolution of fibrin by the fibrinolytic system depends upon the generation of a proteolytic enzyme, plasmin, from an inactive plasma precursor, plasminogen (Christensen and MacLeod, 1945). Plasminogen activation in blood is due to a heatlabile activator which can be demonstrated in subjects under physiological circumstances (Fearnley, Revill, and Tweed, 1952; Flute, 1960a and b; Sawyer, Fletcher, Alkjaersig, and Sherry, 1960). Free plasmin cannot be detected in the circulating blood, even in the presence of free activator (Sherry, Lindemeyer, Fletcher, and Alkjaersig, 1959; Sawyer, Alkjaersig, Fletcher, and Sherry, 1960), for such plasmin is rapidly neutralized by circulating antiplasmins, of which two types have been described (Norman, 1958; Norman and Hill, 1958).

The human antiplasmin which migrates electrophoretically with the alpha-2 globulins combines rapidly and reversibly with plasmin (Norman, 1960) and predominates in inhibitory effect over the alpha-1 migrating antiplasmin (Mann, Cotton, and Jackson, 1966). Plasmin-antiplasmin neutralization may be, therefore, predominantly rapid and reversible, so forming a neutralized complex existing as a reservoir of fibrinolytic enzyme which can dissociate in the presence of fibrin (Ambrus and Markus, 1960).

The present study has been undertaken in order to Received for publication 2 January 1967. determine the physiological activity of certain parameters of this system.

\section{MATERIALS}

The following were used:

IN TESTS OF ANTI-UROKINASE ACTIVITY AND ANTIPLASMIN ACTIVITY Fibrinogen, human, grade L (bottles of $1 \mathrm{~g}$.) Kabi Pharmaceuticals Ltd.; plasminogen, human grade B (100 casein units/vial) Kabi Pharmaceuticals Ltd.; plasmin, human, grade B (20 casein units/vial) Kabi Pharmaceuticals Ltd.; urokinase reference standard, human (2,400 Ploug units/vial) Leo Laboratories Ltd.; thrombin reagent, bovine, $(2,500$ units/vial $)$ Leo Laboratories Ltd.; calcium chloride dried (Analar)

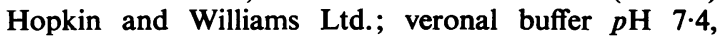
$0.154 \mathrm{M}$; sodium diethyl barbiturate $11.745 \mathrm{~g}$.; sodium chloride $14.67 \mathrm{~g}$.; hydrochloric acid 0.1 N $430 \mathrm{ml}$.; distilled water to 2 litres.

IN DILUTE BLOOD CLOT LYSIS TIME ESTIMATIONS Thrombin, bovine (5,000 units/vial) Parke-Davis \& Co.,

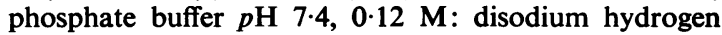
phosphate $9.47 \mathrm{~g}$. in 1 litre distilled water, to which was added potassium dihydrogen phosphate $3.02 \mathrm{~g}$. dissolved in $250 \mathrm{ml}$. distilled water.

\section{METHOD}

A total of 80 persons have been examined, comprising 10 males and 10 females in each of the age groups: 20-29 years, 30-39 years, 40-49 years, and 50-59 years. All 80 subjects were in normal employment and free from overt evidence of disease. Pre-menopausal females were examined in the immediately post-menstrual week. Blood samples from each of the 80 subjects were tested at 10 a.m. and 4 p.m. on one day only. 
Sixteen of these volunteers, comprising two males and two females in each of the four age groups, participated in an extension of the experiment in which blood samples were tested at 10 a.m. and 4 p.m. on five consecutive working days. In each of these age groups of four subjects, one male and one female had a dilute blood clot lysis time of under 4.5 hours; the remaining male and female had a value in excess of this arbitrary limit.

On each day of examination egg, cheese, and fried dishes were excluded from the breakfast taken by each volunteer and the subjects were rested for 15 minutes before venesection which was performed without venous compression, using chilled, plastic disposable syringes and siliconized No. 1 gauge needles.

On each blood sample, except when otherwise stated, the following tests were undertaken:

DILUTE BLOOD CLOT LYSIS TIME In duplicate, by the method of Fearnley, Balmforth, and Fearnley (1957) with the end point modified as described by Fearnley and Chakrabarti (1962). Lysis times in this test are, in the majority of subjects, of two to seven hours' duration and are inversely related to fibrinolytic activity.

PLASMA ANTI-UROKINASE ACTIVITY This was estimated twice on coded aliquots of each specimen by an adaptation of the method of Mann (1966). Individual tests were carried out by adding to $1 \mathrm{ml}$. of plasma (or $1 \mathrm{ml}$. veronal buffer $p \mathrm{H} 7.4$ in the control tubes) $0.6 \mathrm{ml}$. (5 mg.) human fibrinogen solution, $0 \cdot 1 \mathrm{ml}$. $(2.5 \mathrm{CU})$ human plasminogen solution and $0.3 \mathrm{ml}$. of a mixture containing 50 Ploug units urokinase, 0.296 mg. calcium chloride dried, and 5 units thrombin. Veronal buffer, $p \mathbf{H} 7 \cdot 4$, was used as diluent for all reagents which, with the individual tests, were assembled in an ice-water bath at $4^{\circ} \mathrm{C}$. Tests were undertaken in batches of 10 with a control, and the urokinase-containing solution was added to successive tubes in the batch at 15 -second intervals. Each tube was retained at $4^{\circ} \mathrm{C}$. for exactly five minutes before individually timed transfer to a water bath at $37^{\circ} \mathrm{C}$. Lysis times were commenced the moment the urokinase was added.

Under these conditions lysis times, both in the presence and absence of the plasma inhibitors, are linearly related to activator concentration over a critical range, which includes the urokinase concentration used, when the results are expressed on double logarithmic graph paper. Lysis times are directly related to inhibitory activity.

PLASMA ANTIPLASMIN ACTIVITY This was estimated by adding to $1 \mathrm{ml}$. diluted plasma (1 part plasma to 4 parts

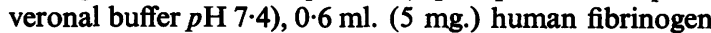
solution and $0.2 \mathrm{ml}$. of a mixture containing $1.5 \mathrm{CU}$ human plasmin and 5 units thrombin. Technical details and controls were similar to those used in the previous method.

\section{RESULTS}

The mean values, standard deviations (for a unit observation), and mean differences for the observations in each age group of 10 subjects in the study involving 80 volunteers are given in Tables I and II. The results of the tests of plasma anti-urokinase activity in 16 selected subjects examined on five consecutive days are given in Table III.

PlASMA ANTI-UROKINASE ACTIVITY From Table I it is evident that mean plasma anti-urokinase activity was, in all age groups, considerably greater in females than in males. This sex difference reached significant proportions $(P=0.05)$ both at 10 a.m. and 4 p.m. in three of the four age groups examined.

As shown in Table III mean plasma anti-urokinase activity was consistently, and highly significantly $(P=0.01)$, greater in females than in males, both at 10 a.m. and 4 p.m. on each of the five days of the study in 16 subjects, and on the overall mean value of all five days. Thus, mean plasma anti-urokinase activity has been found to be considerably greater in women than in men in a manner which is consistent throughout these experiments. This observation applies to group mean values and not necessarily to individual male and female subjects.

The biological significance of this sex difference in

TABLE I

PLASMA ANTI-UROKINASE ACTIVITY (SECONDS) ${ }^{1}$

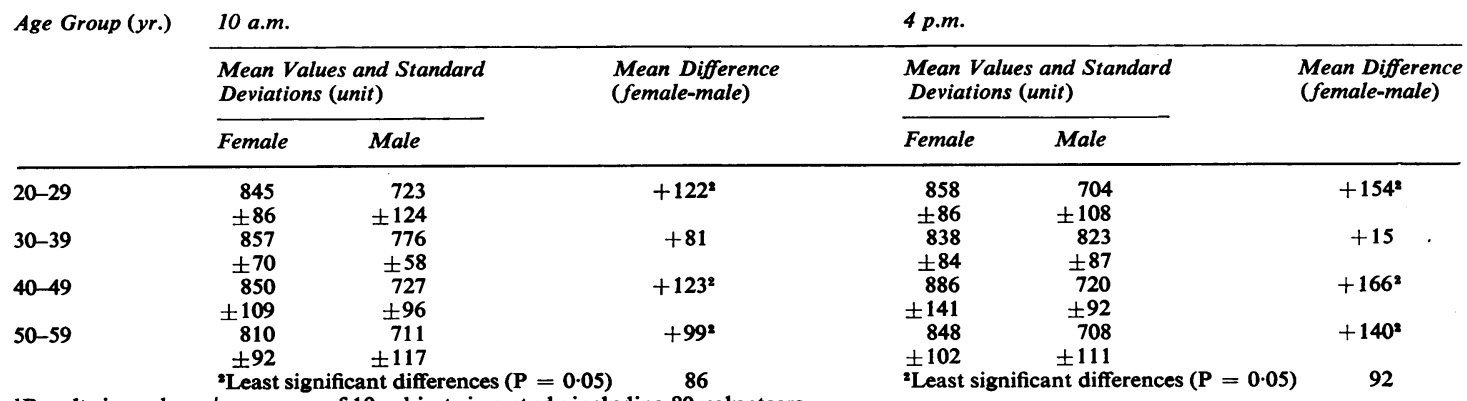

${ }^{1}$ Results in each sex/age group of 10 subjects in a study including 80 volunteers. 
TABLE II

DILUTE BLOOD CLOT LYSIS TIME (HOURS) ${ }^{1}$

\begin{tabular}{|c|c|c|c|c|c|c|}
\hline \multirow[t]{3}{*}{ Age Group (yr.) } & \multicolumn{3}{|l|}{ Males } & \multicolumn{3}{|c|}{ Females } \\
\hline & \multicolumn{2}{|c|}{$\begin{array}{l}\text { Mean Values and Standard } \\
\text { Deviations (unit) }\end{array}$} & \multirow[t]{2}{*}{$\begin{array}{l}\text { Mean Difference } \\
(4 \text { p.m. }-10 \text { a.m. })\end{array}$} & \multicolumn{2}{|c|}{$\begin{array}{l}\text { Mean Values and Standard } \\
\text { Deviations (unit) }\end{array}$} & \multirow[t]{2}{*}{$\begin{array}{l}\text { Mean Difference } \\
\text { (4 p.m.-10 a.m.) }\end{array}$} \\
\hline & 4 p.m. & 10 a.m. & & 4 p.m. & 10 a.m. & \\
\hline $20-29$ & $\begin{array}{r}4.42 \\
+1.06\end{array}$ & $\begin{array}{r}5.58 \\
\pm 2.32\end{array}$ & $-1 \cdot 16$ & $\begin{array}{r}4.70 \\
+1.88\end{array}$ & $\begin{array}{r}5.08 \\
\pm 1.92\end{array}$ & -0.38 \\
\hline $30-39$ & $\begin{array}{r}3.72 \\
\pm 0.81\end{array}$ & $\begin{array}{r}5.05 \\
\pm 3.06\end{array}$ & $-1 \cdot 33^{2}$ & $\begin{array}{r}3.80 \\
\pm 0.68\end{array}$ & $\begin{array}{r}4.95 \\
\pm 1.55\end{array}$ & $-1 \cdot 15$ \\
\hline $40-49$ & $\begin{array}{r}4 \cdot 70 \\
\pm 1 \cdot 78\end{array}$ & $\begin{array}{r}5 \cdot 10 \\
\pm 1 \cdot 50\end{array}$ & -0.40 & $\begin{array}{r}4.35 \\
+1.67\end{array}$ & $\begin{array}{r}4.68 \\
\pm 2 \cdot 17\end{array}$ & -0.33 \\
\hline $50-59$ & $\begin{array}{r}4.10 \\
\pm 1.06 \\
2 \text { Least }\end{array}$ & $\begin{array}{r}6.08 \\
\pm 4.70 \\
\text { ant difference }\end{array}$ & $\begin{array}{r}-1.98^{2} \\
1.31\end{array}$ & $\begin{array}{r}4 \cdot 15 \\
\pm 1 \cdot 26 \\
{ }^{2} \text { Least s }\end{array}$ & $\begin{array}{r}4.48 \\
\pm 1.46 \\
\text { ant difference }\end{array}$ & $\begin{array}{r}-0.33 \\
1.31\end{array}$ \\
\hline
\end{tabular}

TABLE III

PLASMA ANTI-UROKINASE ACTIVITY (SECONDS) ${ }^{1}$

\begin{tabular}{|c|c|c|c|c|c|c|}
\hline \multirow[t]{3}{*}{ Day } & \multicolumn{3}{|l|}{10 a.m. } & \multicolumn{3}{|l|}{4 p.m. } \\
\hline & \multicolumn{2}{|c|}{$\begin{array}{l}\text { Mean Values and Standard } \\
\text { Deviations (unit) }\end{array}$} & \multirow[t]{2}{*}{$\begin{array}{l}\text { Mean Difference } \\
\text { (female-male) }\end{array}$} & \multicolumn{2}{|c|}{$\begin{array}{l}\text { Mean Values and Standard } \\
\text { Deviation: (unit) }\end{array}$} & \multirow[t]{2}{*}{$\begin{array}{l}\text { Mean Difference } \\
\text { (female-male) }\end{array}$} \\
\hline & Female & Male & & Female & Male & \\
\hline 1 & $\begin{array}{r}664 \cdot 8 \\
\pm 50 \cdot 5\end{array}$ & $\begin{array}{r}568 \cdot 8 \\
\pm 54 \cdot 8\end{array}$ & $+96 \cdot 0^{2}$ & $\begin{array}{r}662.2 \\
\pm 67 \cdot 2\end{array}$ & $\begin{array}{r}565 \cdot 6 \\
\pm 68 \cdot 3\end{array}$ & $+96 \cdot 6^{2}$ \\
\hline 2 & $\begin{array}{r}551 \cdot 6 \\
\pm 52 \cdot 3\end{array}$ & $\begin{array}{r}465 \cdot 9 \\
\pm 46 \cdot 0\end{array}$ & $+85 \cdot 7^{2}$ & $\begin{array}{r}547 \cdot 0 \\
\pm 47 \cdot 4\end{array}$ & $\begin{array}{r}491 \cdot 3 \\
\pm 49 \cdot 9\end{array}$ & $+55 \cdot 7^{2}$ \\
\hline 3 & $\begin{array}{r}596.6 \\
\pm 63.5\end{array}$ & $\begin{array}{r}523.4 \\
\pm 42.0\end{array}$ & $+73 \cdot 2^{2}$ & $\begin{array}{r}611 \cdot 7 \\
\pm 69 \cdot 3\end{array}$ & $\begin{array}{r}535 \cdot 4 \\
\pm 52 \cdot 2\end{array}$ & $+76 \cdot 3^{2}$ \\
\hline 4 & $\begin{array}{r}571 \cdot 7 \\
\pm 71 \cdot 7\end{array}$ & $\begin{array}{r}500 \cdot 8 \\
\pm 51 \cdot 7\end{array}$ & $+70 \cdot 9^{2}$ & $\begin{array}{r}589 \cdot 2 \\
\pm 74 \cdot 6\end{array}$ & $\begin{array}{r}505 \cdot 4 \\
\pm 49 \cdot 7\end{array}$ & $+83 \cdot 8^{2}$ \\
\hline 5 & $\begin{array}{r}585.9 \\
\pm 68.9 \\
2 \text { Least si }\end{array}$ & $\begin{array}{l}493.8 \\
\pm 66.8 \\
\end{array}$ & $+92 \cdot 1^{2}$ & $\begin{array}{r}588 \cdot 2 \\
\pm 60 \cdot 1\end{array}$ & $\begin{array}{r}505 \cdot 1 \\
\pm 49 \cdot 9\end{array}$ & $+83 \cdot 1^{2}$ \\
\hline All days & $\begin{array}{l}{ }^{2} \text { Least si } \\
\text { Least sig }\end{array}$ & $\begin{array}{l}\text { ant differences }(P=0.01) \\
\text { ant differences }{ }^{3}(P=0.01)\end{array}$ & $\begin{array}{r}52 \cdot 9 \\
+83 \cdot 6^{3} \\
23 \cdot 7\end{array}$ & $\begin{array}{l}{ }^{2} \text { Least } \\
\text { Least } \mathrm{s}\end{array}$ & $\begin{array}{l}\text { cant difference } \\
\text { ant differences }\end{array}$ & $\begin{array}{c}52 \cdot 9 \\
+79 \cdot 1^{3} \\
23 \cdot 7\end{array}$ \\
\hline
\end{tabular}

${ }^{1}$ Results on each day in the study including 16 volunteers.

anti-urokinase activity may be appreciated from the Trasylol reference curve for the experimental system used (Mann, 1966). The difference between the mean male and female anti-urokinase levels would be produced by a concentration of approximately 3.5 Kallikrein inhibitor units of Trasylol $/ \mathrm{ml}$., or approximately 10,000 K.I. units of Trasylol in the circulating plasma volume.

Mean plasma anti-urokinase activity was not consistently and significantly affected either by age or time of day. Within the limits examined, day-today variations in plasma anti-urokinase activity were of limited degree in individual patients who tended to have a characteristic value within the group. In the extended study of 16 subjects variations in the biological materials employed in the tests may account for part of the observed variations in inhibitory activity between days, but not within days.

PLASMA ANTIPLASMIN ACTIVITY Plasma antiplasmin activity was examined at 10 a.m. on day 5 only in the study including 16 subjects. On this occasion, the mean value in females was $193.3 \pm 50.6$ seconds. In males this mean value was $153.0 \pm 35.8$ seconds. Thus, mean antiplasmin activity was $40 \cdot 3$ seconds greater in females than in males but this difference does not reach significant proportions (least significant difference 50.2 seconds at the $5 \%$ level of confidence). However, the greater mean antiplasmin activity of females is in accordance with the more clearly established greater mean anti-urokinase activity in this sex. In individual male and female subjects the actual antiplasmin value observed did not correlate with the individual level of antiurokinase activity.

DILUTE BLOOD CLOT LYSIS TIME As shown in Table II, mean dilute blood clot lysis time was less, in both sexes and all age groups, at 4 p.m. than at 10 a.m. This difference was of variable degree and reached significant proportions in only two age groups at 10 a.m. The findings support the concept of a 
diurnal variation with greater plasminogen activator activity in the afternoon than in the morning in most subjects examined.

Mean dilute blood clot lysis time variations due to age and sex were insignificant or inconsistent between groups.

\section{CONCLUSIONS}

Fibrinolytic activity has been previously shown to exhibit a diurnal variation and is greater during the day than at night (Fearnley et al., 1957; Billimoria, Drysdale, James, and Maclagan, 1959; Buckell and Elliott, 1959; Moser, 1966). In the current study involving 80 subjects a similar diurnal variation has been detected between the results at 10 a.m. and those at 4 p.m. when mean fibrinolytic activity tends to be greater.

Fibrinolytic activity has been reported to be unaffected by age (Fearnley, Chakrabarti, and Avis, 1963 ) and the present findings agree with this conclusion, although subjects older than 60 years were not included in the study.

Fibrinolytic activity, as shown by the euglobulin lysis time, has been variously reported to be significantly greater in females (Cash, 1966); not significantly different between the sexes (Beller, Goebelsmann, Douglas, and Johnson, 1964; Brakman, Albrechtsen, and Astrup, 1966), and greater in males (Menon, 1966). Marx and Rovatti (1952) found shorter whole-plasma clot lysis times in men compared with women in the inter-menstrual phase. The present study, using the dilute blood clot lysis time technique and comparing males with post-menstrual females, has shown no significant difference between the mean fibrinolytic activity of the sexes.

Antiplasmin levels in normal persons have been found to vary between narrow limits only (Norman, 1960) and have been reported to be unaffected by sex or age (Paraskevas, Nilsson, and Martinsson, 1962). The studies reported here confirm that inhibitory values vary only between relatively narrow limits in individual subjects but show a consistently and significantly greater mean plasma anti-urokinase activity in females compared with males.

I wish to thank the Board of Pfizer Limited for permission to publish this paper and Dr. G. R. Fearnley and Dr. P. T. Flute for their interest and advice.

I am grateful to Dr. W. J. Keating and Sister C. Pickles of Pfizer Limited, for their clinical cooperation. I express my gratitude to the volunteers who have participated and my medical colleagues who have undertaken collection of the necessary blood samples.

Finally, I wish to acknowledge the statistical advice of Mr. P. Avis and Mr. T. Attwell of Pfizer Limited.

\section{REFERENCES}

Ambrus, C. M., and Markus, G. (1960). Amer. J. Physiol. (Lond.), 199, 491.

Beller, F. K., Goebelsmann, U., Douglas, G. W., and Johnson, A. (1964). Obstet. and Gynec., 23, 12.

Billimoria, J. D., Drysdale, J., James, D. C. O., and Maclagan, N. F (1959). Lancet, 2, 471.

Brakman, P., Albrechtsen, O. K., and Astrup, T. (1966). Brit. J. Haemat., $12,74$.

Buckell, M., and Elliott, F. A. (1959). Lancet, 1, 660.

Cash, J. D. (1966). Brit. med. J., 2, 502.

Christensen, L. R., and MacLeod, C. M. (1945). J. gen. Physiol., 28. 559.

Fearnley G. R., Balmforth, G., and Fearnley, E. (1957). Clin. Sci., $16,645$.

, and Chakrabarti, R. (1962). Lancet, 2, 128.

- - , and Avis, P. R. D. (1963). Brit. med. J., 1, 921. Revill, R., and Tweed, J. M. (1952). Clin. Sci., 11, 309.

Flute, P. T. (1960a). The Fibrinolytic system of human plasma. Thesis, M.D., University of London.

(1960b). In Proceedings of the Seventh Congress of the European Society of Haematology, London, 1959, pt. 2, p. 894, edited by E. Neumark. Karger, Basel.

Mann, R. D. (1966). J. clin. Path., 19, 233.

- Cotton, S., and Jackson, D. (1966). Ibid., 19, 185.

Marx, R. and Rovatti, B. (1952). Haematologica, 36, 685.

Menon, I. S. (1966). Brit. med. J., 3, 829.

Moser, K. M. (1966). Fed. Proc., 25, 94.

Norman, P. S. (1958). J. exp. Med., 108, 53.

(1960). Amer. J. Cardiol., 6, 390.

, and Hill, B. M. (1958). J. exp. Med., 108, 639.

Paraskevas, M., Nilsson, I. M., and Martinsson, G. (1962). Scand. J. clin. Lab. Invest., 14, 138.

Sawyer, W. D., Alkjaersig, N., Fletcher, A. P., and Sherry, S. (1960) Thrombos. Diathes. haemorrh. (Stuttg.), 5, 149.

- Fletcher, A. P., Alkjaersig, N., and Sherry, S. (1960). J. clin. Invest., 39, 426.

Sherry, S., Lindemeyer, R. I., Fletcher, A. P., and Alkjaersig, N. (1959), Ibid., 38, 810. 